\title{
METHODOLOGY OF IMPLEMENTATION ENERGY EFFICIENCY IN MAMUFACTURING
}

\author{
MicieTA, B. \& BinASOVA, V.
}

Abstract: This paper presents research requirements that have been identified as important for manufacturing enterprises in sustainable production and description of methodology for reducing the energy intensity and environmental impacts of production processes. The development of advanced industrial engineering and new energy efficient technologies are essential for security of supply, sustainability and competitiveness of industrial sector. Energy and environment related research has contributed strongly to energy efficiency. With development of sustainable production is necessary to pay attention of reducing energy consumption and increasing the energy efficiency in manufacturing processes. The paper demonstrates that there exists a relationship between system elements and methods for energy management systems in industrial enterprises. It concludes by deriving requirements for energy management in production that future collaborative research projects should address.

Key words: energy efficiency in manufacturing, cost optimization, manufacturing, advanced industrial engineering, sustainable production
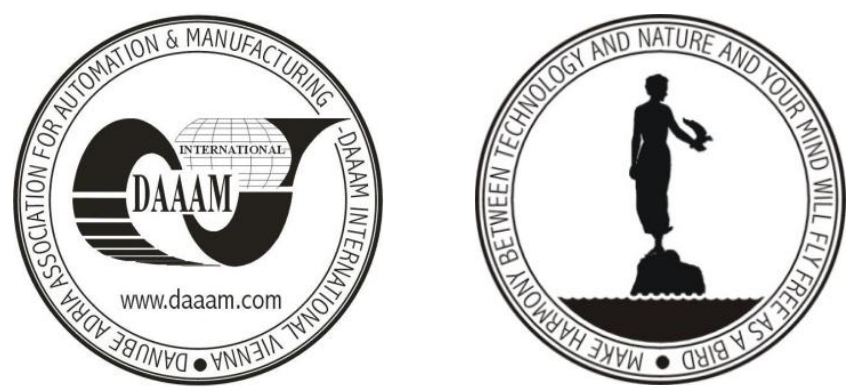

Authors' data: Prof. Ing. PhD. Micieta, B[ranislav]; Ing. Binasova, V[ladimira], University of Zilina, Univerzitna 8215/1, 01 026, Zilina, Slovakia, branislav.micieta@fstroj.uniza.sk, vladimira.binasova@fstroj.uniza.sk,

This Publication has to be referred as: Micieta, $\mathrm{B}$ [ranislav] \& Binasova, V[ladimira] (2014). Methodology of Implementation Energy Efficiency in Mamufacturing, Chapter 28 in DAAAM International Scientific Book 2014, pp.357364, B. Katalinic (Ed.), Published by DAAAM International, ISBN 978-3-90150998-8, ISSN 1726-9687, Vienna, Austria

DOI: $10.2507 /$ daaam.scibook.2014.28 
Micieta, B. \& Binasova, V.: Methodology of Implementation Energy Efficiency in ...

\section{Introduction}

The purpose of the methodology for reducing the energy intensity and environmental impacts of production processes describes two related concepts, which contribute methodically to the aim, and the current progress in realizing them. One part of the research is the energy efficient production planning for systematically identifying and implementing energy efficiency improvement opportunities in factory planning processes. It should provide energy efficiency knowledge in a concentrated and structured manner for a knowledge management system. Another questions are integration of holistic energy management approaches to the next generation of manufacturing enterprises, where the aim of the system is the ability to maintain their competitiveness in the market through the production of sufficient quantities of lowcost, high products quality that meet customer demand and the industrial problems and needs in terms of integrating energy efficiency in production management. Research issue of increasing energy efficiency is formulated into 5 key areas (Fig. 1).

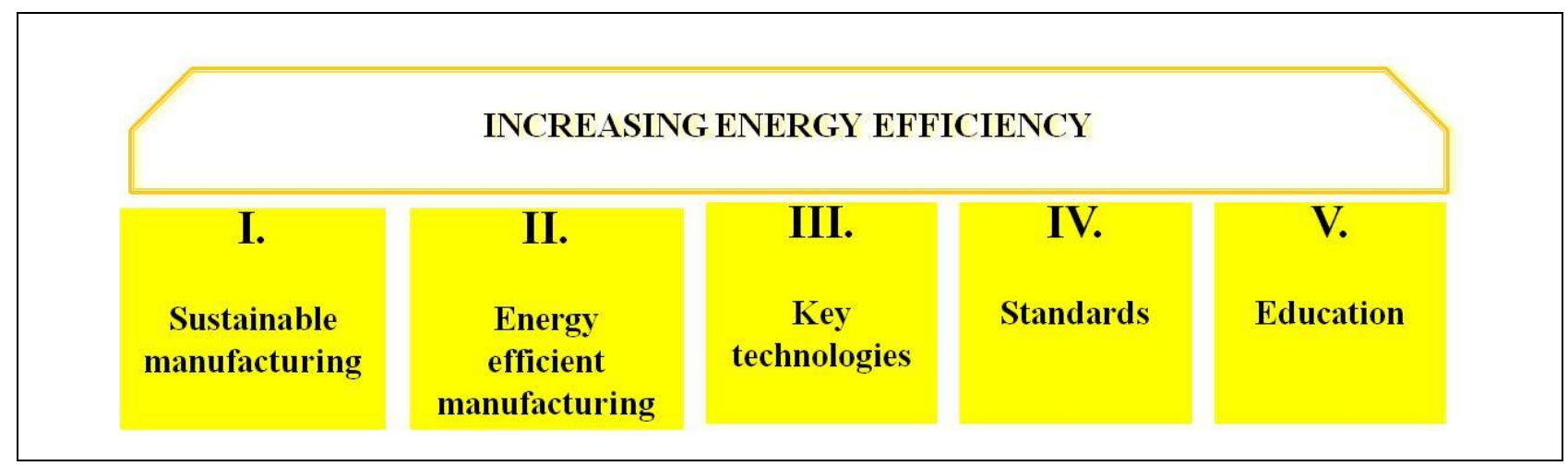

Fig. 1. Key research issues of energy efficiency

\subsection{Sustainable manufacturing}

Sustainability of the production consists in the ability to build such a production schedule, which will be the purpose of preparing marketing aspects. This means producing of products, which are demanded by the market and at the same time are chosen such means of production, production systems and processes, which will provide production program to perspective market. Sustainability of the production is a specific area, which addresses whether it is properly constructed sustainable production program and the market will demand products. It is a combination of marketing, strategic decision making and consideration of technical progress, technical capabilities, which allow the market to provide products. In area of industrial production is sustainability of the production an accurate decision relating to the choice of the production program and forecasts of market needs.

\subsection{Energy efficient manufacturing}

In the context of this issue, it is necessary to search answers to the following questions: What are the industrial problems and needs in terms of integrating energy efficiency in production management? The aim of this study is to identify the corresponding problems and needs in the industry, which are tied to energy 
efficiency. Full options, which are important in designing and planning production processes, for example lighting equipment setup or educating people to not to waste energy. It can be anything, why industrial engineer is scope so that these problems and needs were able to first find, identify, then look for solutions and propose measures. How can be satisfied these needs with new concepts of monitoring, management and increasing energy efficiency in the context of energy management in production? These needs can be satisfied by using the tools of industrial engineering, which is achieved influence of energy intensity. Here is the hidden meaning of the work, which is based on establishing a methodology for reducing the energy intensity of production processes. The one of the key areas for achieving energy efficiency is energy efficient production, then the work is specifically within the Department of industrial engineering focuses on designing production systems and manufacturing processes, for their management and improvement can be done to energy efficient manufacturing.

\subsection{Key technologies}

The question of technologies during the development of the whole civilization has been and always will be very important, because once a person some technology can devise and implement, then he is looking for the possibility of applying for it. In the development of technology is important to ensure that energy consumption is as low, as it can. It is not an easy task, therefore, an attempt is designed information technology and hardware across any technology or equipment so that the least energy consuming. But it is a matter of design of technical facilities through which those technologies are implemented. It forms one single chapter, because it is the task of those who design technology and equipment, through which these technologies are implemented. An attempt is to develop such technology, which not only meeting the requirements of the uses of the technology, but also had the least energy consuming.

\subsection{Standards}

Standards are rules that are elected by people in industrial manufacturing or by providing services. In standards are emphasized that the rules are such that people had in mind the need to reduce energy intensity and to seek such standards, which respect the need to reduce energy consumption.

\subsection{Education}

Education is a very important area, because training or education of people to make really paid attention to the need to reduce energy intensity not only production but also for all activities. It is the question of removing waste. Therefore, in the operation of industrial engineering include the care of energy because energy is one of the important resources that enter the process. Therefore, in the education of industrial engineers, who have from the mission of industrial engineering in itself encoded removing all sources of waste, such as waste material removed, unnecessary work, so it is also necessary to pay attention to the elimination of wasted energy consumption. Therefore was created the methodology for reducing the energy 
Micieta, B. \& Binasova, V.: Methodology of Implementation Energy Efficiency in ...

intensity of production processes. It is necessary to prepare people to be able to implement these changes.

\section{Definition of the problem statement of energy efficient production planning}

Energy efficiency indicators, or more generally energy performance indicators, give the links between energy use and some relevant monetary or physical indicators measuring the demand for energy services. They may be defined at different levels of aggregation in terms of energy demand, e.g. economy-wide, sector, sub-sector, end use, technology, process and device. Energy performance indicators can be used to quantify improvements in energy efficiency, use and consumption at the organization, facility, system and process or equipment level. Energy performance indicators are a measure of energy intensity used to gauge effectiveness of energy management efforts. These indicators, previously defined during the preparation of the company's energy policy, express a quantitative value of the energy performance measurement. The value of energy consumption has to be related to a reference variable that allows it to be correctly interpreted. For example: $\mathrm{kWh} / \mathrm{m}^{2}, \mathrm{kWh} / \mathrm{m}^{3}$, etc.

Responsibility for determining the energy performance indicators typically rests with the energy management representative and may involve other members of the energy control team, as well as management. Resources to complete the energy performance indicators determination process are allocated by top management. The concept of energy performance includes energy use, energy efficiency and energy consumption. The organization can choose between a wide range of energy performance activities. For example, the organization could reduce peak demand, utilize surplus or waste energy or improve the operations of its systems, processes or equipment. Energy savings and reducing of energy waste are often subservient to production targets and decisions about changing machine states involve weighing up a complex set of goals and constraints. These include constraints such as production capacity, predicted inventory and product priorities as well as soft constraints as technician skill level, engineering requests and autonomous maintenance. The following figure 2 shows how based on a series of inputs and outputs of energy planning, the key meeting points are structured. This diagram is not intended to represent the details of a specific organization. The information in the energy planning diagram is not exhaustive and there may be other details specific to the organization or particular circumstances.

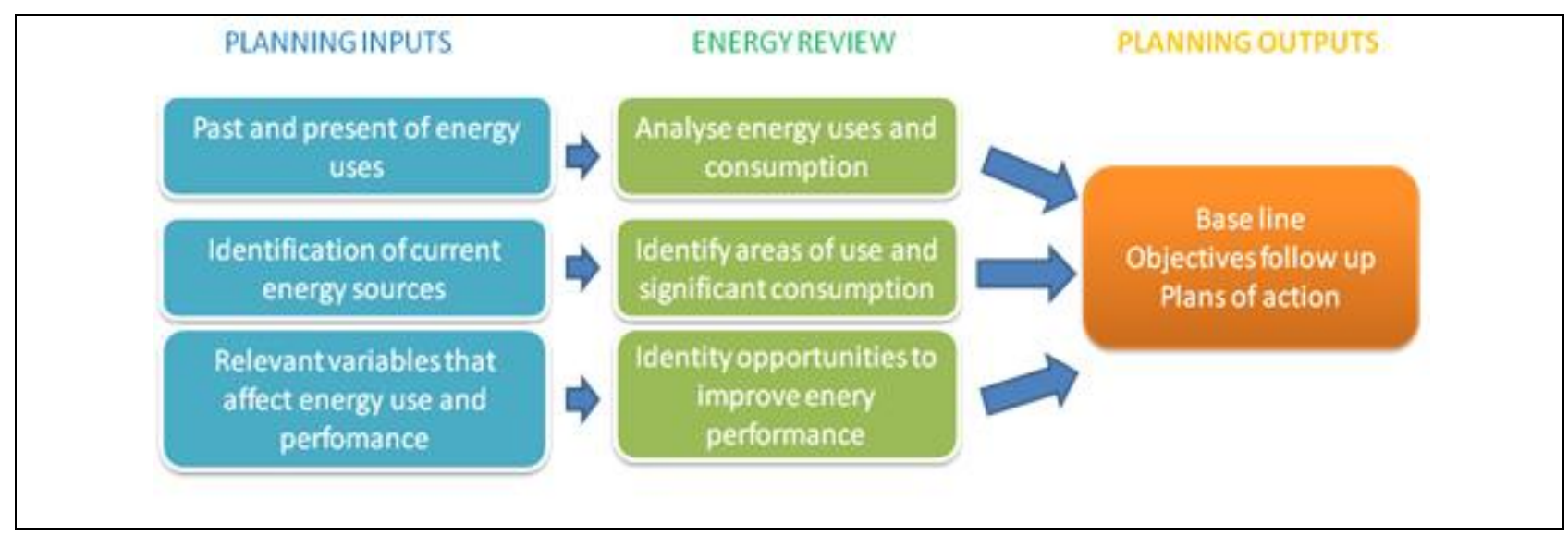

Fig. 2. Basic diagram of energy planning 
Energy issues become especially significant in phases 3-6 of the factory planning process:

- phase 1: setting of objectives,

- phase 2: establishment of the project basis,

- phase 3: concept planning,

- phase 4: detailed planning,

- phase 5: preparation for realization,

- phase 6: monitoring of realization,

- phase 7: rump-up support.

Sensor data out of processes can especially help to improve the detailing by showing the economical advantages of information in the right granularity. Monitoring systems are improving the future factory by the simplification of decision-making. The collaboration of the planning team is particularly supported by extensive data mining and monitoring.

\subsection{Eco-innovation against crisis}

Nowadays, it is appropriate to use the full potential of eco-innovation, environmental protection, to promote competitiveness, growth and job creation (Magvaši \& Gregor, 2013). Cleantech is also economical and ecological solutions to enhance productivity, efficiency, saving energy costs and thus the environment (Hnát, 2013). Currently, the cleantech referred to as a separate industry. Energy generated from naturally renewable sources is ecologically undisputed and largely contributes to generating primary energy. Using energy product such as wood biomass could also enable partial energy independence for certain countries that fulfil or even exceed their economic needs for biomass sources. (Krajnc \& Dolsak, 2013)

\section{Integration of holistic energy management approaches to the next generation of manufacturing enterprises - results and future research}

An integration of energy management systems in the experimental and digital factory purposes to bridge the gaps between factory planning and factory operation on the hand and energy management on the other hand. That means that the production system including facility management has to be connected to business information systems such as enterprise resource planning (ERP), manufacturing execution system (MES), energy management and energy monitoring in a holistic way. Therefore suitable components and methods are developed. Hardware such as transmission technology, sensors, measuring devices, actuators and systems for indirect load control is accessed by middleware with functions for load profile recording, data mapping, load forecast, identification of potential flexibility and a self-learning data preparation, to the business information systems.

In result the business information systems are provided with input of sensor data of a new quality and level of detail so that the identified potential for the reduction of energy demand and cost by dynamic load balancing can be utilized. With the input of 
the Energy Management Systems it becomes possible to synchronize information gathering and energy budgeting. That is a clear advantage to conventional systems which don't incorporate load information. Importance is placed on the ability to adjust quickly to the new production of existing requirements and the turbulent states, which may be internal or external (Mičietová \& Čilliková, 2009). The aim of the system is the ability to maintain their competitiveness in the market through the production of sufficient quantities of low-cost, high products quality that meet customer demand (Mičietová, et al., 2009). Due to the fact it is necessary that future generations of manufacturing companies could autonomously react to generating changes. Enterprises need to have an integrated telecommunications network and information technology through which they can transmit the necessary information and dates within the organization (Fig. 3). Customers require specific and innovative products, which can have adverse effects on the environment.

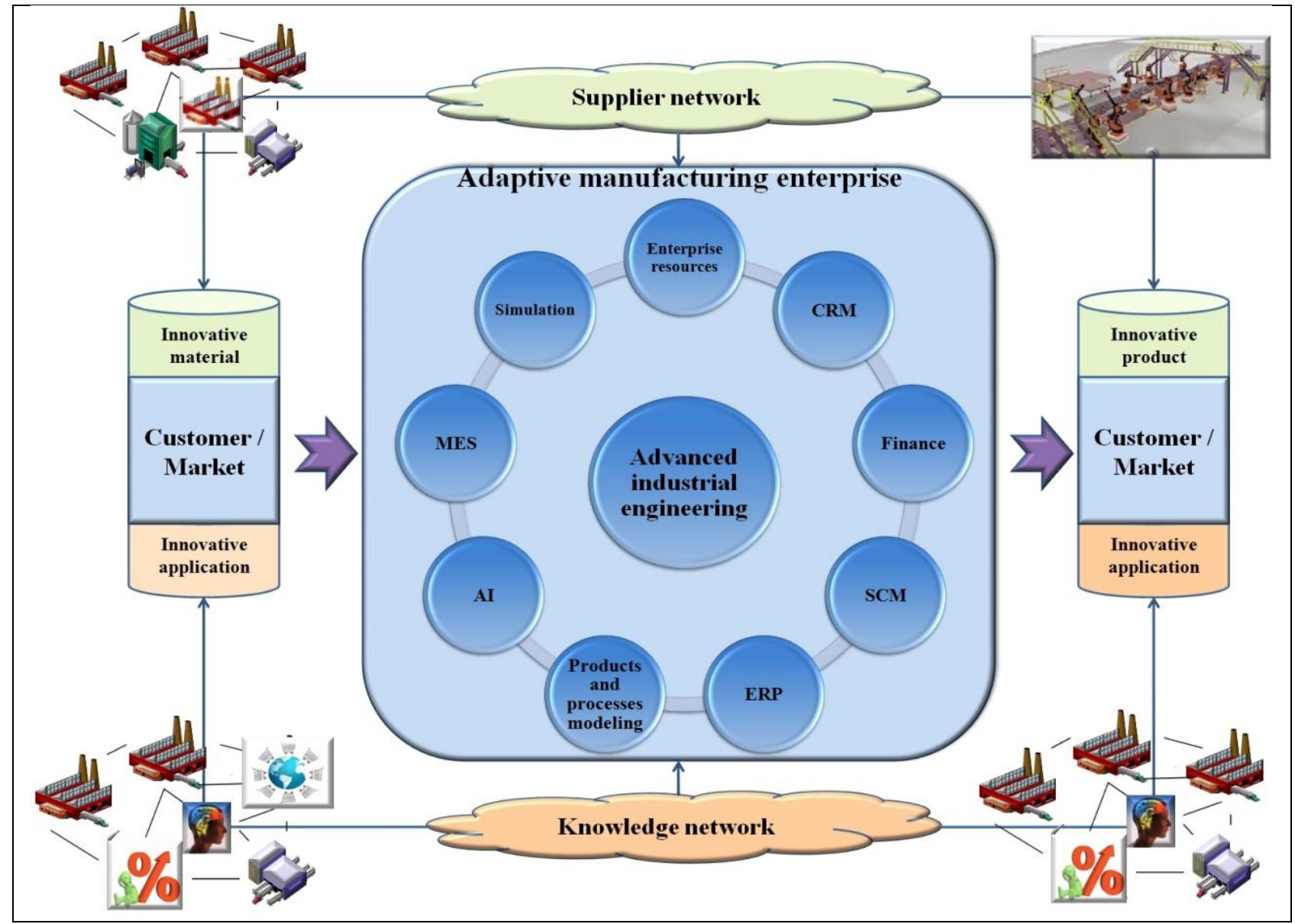

Fig. 3. Network architecture of future manufacturing enterprises

Due to the fact for the development of new product platforms it is necessary to ensure mutual cooperation with partner companies to provide the necessary knowledge to develop new products and solutions on base of sharing experience. At the same time the intention is the development of advanced materials and new approach for analysis. Simultaneously, the customer must specify requirements the through communication interface over which will enterprise obtain documents on draft products: 
- Implementation of unique information technology (Dulina \& Bartánusová, 2013).

- Reliable modelling, monitoring and simulation of manufacturing processes.

- Reliable detection of abnormalities. The sustainability of production.

- Fast reconfiguration depending on the external environment.

The increasingly fluctuating and uncertain demands coupled with the ever changing product and process technologies have pronounced the inability if conventional manufacturing systems to handle the modern challenges efficiently and cost effectively. (Goyal, et al. 2013). The development of sophisticated information technology and intelligent control of business processes is the key to the humanization of human labour (Kohár \& Hrček, 2013). The trend will accelerate depending on the production environment. In production is necessary to use a number of information technology with support of digital engineering (control systems), modelling and monitoring systems (Krajčovič, et al., 2013).

In view of turbulent external environments it is requires a high complexity of supply chain management, which affect the development of software platforms for enterprise resource planning, management of finances and time efficiency performance the contracts. Energy efficiency improvements are attainable with the best available technology and practice. Energy efficient production planning can pay for themselves in energy savings, sometimes within months, and further reduce operation and maintenance costs in the long term (Rahimifard, et al., 2010). Reduce energy expenditure via a structured approach to identifying, measuring and managing energy consumption (Gregor \& Medvecký, 2011). Lean Manufacturing is in direct opposition with traditional manufacturing approaches characterized by use of economic order quantities, utilization, etc. (Rakyta \& Bubeník, 2010).

\section{Conclusion}

This paper presents research of energy efficient production planning in order to reduce of environmental impacts of production systems that have been identified as important for manufacturing enterprises in sustainable production and description of lean processes for reducing the energy intensity and environmental impacts of production processes. The development of advanced industrial engineering and new energy efficient technologies are essential for security of supply, sustainability and competitiveness of industrial sector.

Energy and environment related research has contributed strongly to energy efficiency. With development of sustainable production is necessary to pay attention of reducing energy consumption and increasing the energy efficiency in manufacturing processes. On factory side all sensors and control units are elements of the shops and generate information around events. This can be called "a smart factory". Real time information combined with histories and future (simulation) make it possible to realize a new generation of IT-driven factories and enterprises.

With energy and environment remain important global issues and sustainable development becomes increasingly more important, it is expected that energy efficiency and related environmental indicators will continue to play an important 
role in providing information for policy makers to address national and global energy, environmental, and resource depletion problems. In designing modern factory and logistics systems, energy efficiency plays an important role.

Therefore, new methods, tools and technologies have to be developed. An increase of energy efficiency in the planned systems can be achieved with less effort and in less time. Further research intends to specify the concept and to develop a demonstrator for testing the application by case studies. In further research, results should be transferred to industrial practice.

\section{References}

Dulina, L., Bartánusová, M. (2013). Ergonomics and preventive medicine in companies in Slovak republic and the EU. In: Ergonomics 2013. Zagreb: Croatian Ergonomics Society, pp.81-86, ISSN 1848-9699

Goyal K. K., Jain P. K., Jain M. (2013). Applying Swarm Intelligence to Design the Reconfigurable Flow Lines. Int. Journal of Simulation Modelling, Vol. 12, No. 1, p. 17-26, ISSN 1726-4529

Gregor, M., Medvecký, Š. (2008). Zilina University concept of Digital Factory. In: Communications : scientific letters of the University of Žilina, Vol. 10, No. 2, p. 6066, ISSN 1335-4205

Hnát, J. (2013) Assembly line balancing problem solved by genetic algorithm, In: AIE: monograph, Bielsko-Biała, p. 7-8, ISBN 978-83-927531-6-2

Kohár, R., Hrček, S. (2013). Dynamic analysis of rolling bearings with elastic cage, In: 54th International conference of machine, pp.211-212, ISBN 978-80-7372-986-8

Krajčovič, M. et al. 2013. Intelligent manufacturing systems in concept of digital factory. In: Communications : scientific letters of the University of Žilina, Vol. 15, No. 2, p. 77-87, ISSN 1335-4205

Krajnc M., Dolsak B. (2013). Computer and Experimental Simulation of Biomass Production Using Drum Chipper. Int. Journal of Simulation Modelling, Vol. 12, No. 1, p. 39-49, ISSN 1726-4529

Magvaši, P., Gregor. M. (2013). Advanced industrial engineering and quality of industrial enterprises. In: Quality of Products from the quality of responsibility and innovation, pp. 38-42, ISBN 978-80-553-1466-2, Kosice

Mičietová, A., Čilliková, M. (2009). Technology - cutting, University of Zilina, p. 486, ISBN 978-80-554-0010-5

Mičietová, A., Čilliková, M. and Salaj, J.(2009). Influence of some selected factors on surface quality when cutting by plasma and laser beam. In: Journal of Machine Manufacturing: Design and Manufacturing. Vol. 49, pp. 104-106. ISSN 0016-8580 Rahimifard, S.; Seow, Y. \& Childs, T. (2010). Minimising Embodied Product Energy to support energy efficient manufacturing, Available from: http://www.sciencedirect.com/science/article/pii/S0007850610000491 Accessed: 2014-08-23

Rakyta, M., Bubeník, P. (2010). The economic crisis, the time to develop new approaches technological development. In: Technic. Vol. 8, No. 5, pp. 50-51, ISSN $1337-0022$ 